\title{
Using Multiple Methods to Assess Learning and Outcomes in an Online Degree- Granting Dental Hygiene Program
}

\author{
Emily Springfield, B.A., M.S.Ed.; Anne E. Gwozdek, R.D.H., B.A., M.A.; \\ Melissa Peet, Ph.D.; Wendy E. Kerschbaum, R.D.H., M.A., M.P.H.
}

Abstract: Program evaluation is a necessary component of curricular change and innovation. It ascertains whether an innovation has met benchmarks and contributes to the body of knowledge about educational methodologies and supports the use of evidence-based practice in teaching. Education researchers argue that rigorous program evaluation should utilize a mixed-method approach, triangulating both qualitative and quantitative methods to understand program effectiveness. This approach was used to evaluate the University of Michigan Dental Hygiene Degree Completion E-Learning (online) Program. Quantitative data included time spent on coursework, grades, publications, course evaluation results, and survey responses. Qualitative data included student and faculty responses in focus groups and on surveys as well as students' portfolio reflections. The results showed the program was academically rigorous, fostering students' ability to connect theory with practice and apply evidence-based practice principles. These results also demonstrated that the students had learned to critically reflect on their practice and develop expanded professional identities; going beyond the role of clinician, they began to see themselves as educators, advocates, and researchers. This evaluation model is easily adaptable and is applicable to any health science or other professional degree program. This study also raised important questions regarding the effect of meta-reflection on student confidence and professional behavior.

Ms. Springfield is Instructional Designer, Dental Informatics, University of Michigan; Prof. Gwozdek is Director, Dental Hygiene Degree Completion Programs, Periodontics and Oral Medicine, University of Michigan; Dr. Peet is Assistant Research Scientist, Periodontics and Oral Medicine, University of Michigan; and Prof. Kerschbaum is Director of Dental Hygiene, Periodontics and Oral Medicine, University of Michigan. Direct correspondence and requests for reprints to Ms. Emily Springfield, University of Michigan, 1011 N. University Ave., Room 3052, Ann Arbor, MI 48109; espring@umich.edu.

Keywords: curriculum, dental hygiene education, distance education, teaching assessment, competency-based education, multiple assessment, triangulation, online learning

Submitted for publication 4/28/11; accepted 7/21/11

$\mathrm{O}$ ver the past decade, the American Dental Education Association, especially through its Commission on Change and Innovation in Dental Education (ADEA CCI), has led an initiative for curricular innovation in dental education that keeps pace with the rapid changes in science, technology, and oral health care delivery. Program evaluation is a necessary component of curricular change and innovation. Not only does it ascertain whether an innovation has met benchmarks, but assessment research contributes to the body of knowledge about educational methodologies and supports the use of evidence-based practice in teaching.

Assessment of students' learning and program effectiveness should take place throughout a professional educational program. Evaluation of competence is integral, but also important in providing the opportunity for students to assess their educational experiences as these relate to their personal learning, enduring understanding, attitudes, and values. ${ }^{1-3}$ Program evaluation is also an important element of curriculum management. Thus, assessment should involve all stakeholders: students, faculty members, and administrators. ${ }^{1}$ Productive and meaningful assessment data collection is best when it is ongoing, and continuous improvement results when methods and outcomes are regularly and comprehensively analyzed. ${ }^{1}$

The purpose of this article is threefold. First, it presents a rigorous summative program evaluation model that triangulates a variety of qualitative and quantitative data to perform a systematic and comprehensive program evaluation. This model is easily adaptable and could be applied to any health science or other professional degree program. Second, this model is used to demonstrate programmatic assessment process and results from the University of Michigan (U-M) Dental Hygiene Degree Completion E-Learning Program. The U-M Dental Hygiene Program initiated the systematic development of an e-learning (online) degree completion program in July 2006. This program, which admitted its first students in January 2008, is premised upon proven models for active, collaborative, and reflective learn- 
ing and established best practices for effective online course delivery. ${ }^{4}$ Results from the first two cohorts are presented. Finally, this analysis serves to provide others with an effective model for making evidencebased decisions regarding program development and evaluation.

\section{Background}

The e-learning program consists of ten sevenweek, three-credit-hour courses and one fourteenweek, six-credit-hour course. The thirty-six-credithour curriculum takes two full years to complete. Students proceed as a cohort through the curriculum: everyone takes the same courses in the same order. Unlike many online programs, there are no lectures or tests. Instead, content is delivered primarily through textbooks and primary source literature, and learning is assessed through papers, presentations, and projects.

Comprehensive information about the program design is described in Gwozdek et al. ${ }^{4}$ Its key features are the following:

1. Designed around competencies. The program comprises twenty-three competencies organized into five competency domains: Professional Development and Leadership; Information Literacy and Communication; Health Promotion and Disease Prevention; Evidence-Based Practice; and Community.

2. Emphasizes active learning and application. Students are required to actively engage with course material, community agencies, faculty, and each other. Proof of factual knowledge (e.g., via multiple-choice tests) is deemphasized in favor of applying course material in realistic scenarios, including program planning, field work in community agencies, student teaching in dental hygiene programs, and capstone project experiences.

3. Requires ongoing reflection. Reflection, defined in this program as "critical self-assessment relating to course learning and program competencies," is required at least twice per course. Students also reread their reflections at the end of the program ("meta-reflection") and write final summative self-evaluations. Key terms, as defined in this program, are listed in Table 1.

All enrolled students have completed an associate's degree, and most work full- or part-time in their field. Some have only recently become licensed, while others have worked as hygienists for ten or more years. All fit the profile of adult learners. Eighty percent of the students are from Michigan, and 20 percent live out-of-state. As of 2010, two cohorts have graduated from the program. The results presented here are based on data from both Cohort One $(n=7)$ and Cohort Two $(n=9)$; all students in each cohort participated in the study.

Cohort One, as a group, was an especially motivated and engaged group of students. Four of the seven students in Cohort One maintained an overall "A" average. Cohort Two performed slightly less well academically; they also had more issues with submitting late assignments and did not take advantage of as many opportunities for extra help, such as instructor review of drafts of major papers. Analyzing results from a high-achieving cohort and a more mainstream cohort gives insight into the ap-

Table 1. Definition of key terms used in study

\begin{tabular}{lll} 
Term & \multicolumn{1}{c}{ Definition } & \multicolumn{1}{c}{ Example } \\
\hline Learning & Acquiring new concepts & Reading an article on "How to Write a Program Plan" \\
Application & $\begin{array}{l}\text { Using new knowledge in a realistic } \\
\text { setting }\end{array}$ & Writing a program plan \\
Reflection & Critical self-assessment of learning & Writing about one's ability to "Assess, plan, implement, and \\
& & $\begin{array}{l}\text { evaluate community-based oral health programs" (program } \\
\text { competency 5-4) }\end{array}$ \\
Meta-reflection & $\begin{array}{l}\text { Reviewing reflections and reassess- } \\
\text { ing self, based on the content of the }\end{array}$ & $\begin{array}{l}\text { Rereading all reflections and writing a summary of growth } \\
\text { over the course of the entire program }\end{array}$ \\
& $\begin{array}{l}\text { Perceiving oneself to be competent } \\
\text { Confidence }\end{array}$ & $\begin{array}{l}\text { Stating in a focus group: "I was able to take everything we'd } \\
\text { learned from earlier courses, and I knew how to do it all } \\
\end{array}$ \\
& & without having to ask"
\end{tabular}


plicability of the program's methods to a wide range of students.

The faculty for the program consisted of seven instructors; all faculty members participated in this study. Some faculty members taught more than one course, and two of the instructors were also on the program design team. All accepted the invitation to teach online in addition to their existing duties. All were at least moderately comfortable with computers, three had taken courses online, and one had taught online before. Surveys of faculty members before teaching showed that they believed students learn the same or more in online courses than in face-to-face courses. This is in sharp contrast to recent national surveys that show only 30 percent of faculty members believe online courses have learning outcomes the same or better than face-to-face courses. ${ }^{5}$ This could be attributed to extensive faculty development stressing active online learning before instructors began designing their courses.

\section{Methods}

The assessment plan for this program was developed during the curriculum design phase of the project and follows the triangulation approach. The evaluation program and all evaluation instruments were submitted for Institutional Review Board approval prior to the first student orientation, and the project was granted exempt status.

The goal of triangulation is to generate and analyze data from a variety of sources to explore a research question/phenomenon from multiple perspectives. Thurmond describes five types of triangulation: data source, investigator, methodological, analytical, and theoretical. ${ }^{6}$ This study used three types of triangulation: 1) data source - we collected data from students and faculty members, both anonymously and face-to-face; 2) investigators-multiple researchers/ evaluators were involved in collection and analysis of data; in particular, face-to-face data were collected and cleared of identification by researchers who did not teach in the program to encourage students and faculty to speak freely; and 3) methodological-we used both qualitative and quantitative methods.

Both formative and summative evaluations are necessary parts of a program evaluation plan. Formative evaluation methods were used to gather feedback from students and to improve course delivery as the program progressed in two ways: to make immediate changes to improve the learning experience of the first cohort of students and to improve courses when they were delivered to subsequent cohorts. Surprisingly few changes were needed between Cohorts One and Two. ${ }^{4}$ Summative program evaluation focuses on the effectiveness of the program as a whole. This took place after the graduation of the first two cohorts. The program was evaluated on three dimensions: academic rigor, faculty experience of teaching, and student learning and growth.

A number of evaluation instruments were used to measure program efficacy (Table 2). Quantitative data were obtained through instruments tracking student time spent on coursework, course evaluation results, and student/faculty surveys. Qualitative data were obtained from portfolio reflections and focus groups. Some instruments provided both data types. To reduce the total number of surveys students must complete, questions related to overall program evaluation were included in the required course evaluations.

This first category of evaluation instrument used included student grades, publications, presentations, and awards. Grades of the first two cohorts were analyzed, and the number of publications, presentations, and awards earned for student work completed during the program were counted. Second were student e-learning perceptions surveys (designated here the "student pre-survey" and "student post-survey"). Students were surveyed via anonymous, online survey software during orientation and at graduation. Topics included their expectations about online learning and their readiness and enthusiasm for online learning; questions were based on previously developed surveys used by Mitchell et al. and Wills and Stommel. ${ }^{7,8}$ Third were course evaluations. Evaluations were administered at the end of each course; these gave students the opportunity to provide feedback about individual courses and faculty, as well as more global questions about the program, technology, portfolio, availability of support resources, and number of hours students spent on coursework. Fourth were students' ePortfolio competency reflections. At the end of each seven-week course, the students reflected on their choice of four of the twenty-three program competencies. The reflections were graded by a team of two to four instructors who had achieved a high degree of inter-rater reliability using a standard rubric that assessed the depth of the reflection. At the end of the program, administrators tallied the number of times students reflected on each competency and analyzed the overall depth of all student reflections. Fifth were students' final ePortfolio reflections. At 
Table 2. Assessment measures used in study

\begin{tabular}{|c|c|c|}
\hline Aspect & Evaluation Tool & Quantitative/Qualitative \\
\hline Academic rigor of program & $\begin{array}{l}\text { - Student time spent on coursework } \\
\text { - Curriculum analysis } \\
\text { - ePortfolio reflection counts } \\
\text { - Course evaluations } \\
\text { - Focus groups } \\
\text { - Faculty pre- and post-survey }\end{array}$ & $\begin{array}{l}\text { - Quantitative } \\
\text { - Qualitative } \\
\text { - Quantitative } \\
\text { - Quantitative and qualitative } \\
\text { - Qualitative } \\
\text { - Quantitative and qualitative }\end{array}$ \\
\hline Faculty experience & $\begin{array}{l}\text { - Faculty pre- and post-survey } \\
\text { - Faculty focus groups }\end{array}$ & $\begin{array}{l}\text { - Quantitative and qualitative } \\
\text { - Qualitative }\end{array}$ \\
\hline Student learning and growth & $\begin{array}{l}\text { - Student grades } \\
\text { - Pass/fail rates } \\
\text { - Count of student publications, presentations, } \\
\text { and awards } \\
\text { - Student pre- and post-survey } \\
\text { - Student focus groups } \\
\text { - Final ePortfolio reflections } \\
\text { - Course evaluations }\end{array}$ & $\begin{array}{l}\text { - Quantitative } \\
\text { - Quantitative } \\
\text { - Quantitative } \\
\text { - Quantitative and qualitative } \\
\text { - Qualitative } \\
\text { - Qualitative } \\
\text { - Quantitative and qualitative }\end{array}$ \\
\hline
\end{tabular}

the end of the program, the students reread all their previous ePortfolio reflections and wrote a final summative reflection. These final ePortfolio writings were qualitatively analyzed using the method of constant comparison, which organizes data into conceptual categories and analyzes them to discover social processes and relationships. ${ }^{9,10}$ The final type of evaluation involving students was student focus groups. Focus groups for the first two cohorts were administered by an external program evaluator after the students graduated from the program. The focus group protocol prompted students to discuss the goals of the program, program highlights, challenges, "aha moments," and suggestions for improvement. The focus groups were audiorecorded as well as captured near verbatim by a note taker. These notes were also qualitatively analyzed using the methods of constant comparison and investigator triangulation. ${ }^{9}$

Two types of evaluation involved the faculty. Using e-learning perceptions surveys, faculty members were surveyed via anonymous, online survey software before ("faculty pre-survey") and after ("faculty post-survey") they taught their first online courses. All seven faculty members responded to both surveys. Survey topics included their expectations about online teaching, their readiness and enthusiasm for online teaching, the role of faculty, their perception of the effectiveness of online instruction, and general comments. In addition, two faculty focus groups were held: one with faculty members who had been heavily involved in the design of the program, and one with faculty members who had responsibility for designing and teaching their own courses only. This allowed faculty members to speak freely to the external evaluators who administered the focus groups. The protocol for the focus groups (which were audiorecorded and transcribed) prompted instructors to discuss their perceptions and experiences teaching the online program, including successes, challenges, "aha" moments, and ways in which they altered or changed their teaching practices. The focus group transcripts were also qualitatively analyzed using the method of constant comparison and deductive coding. ${ }^{9}$

These data were gathered from students and faculty members at various points in the program (Figure 1). By gathering data systematically and using existing data sources (grades, course evaluations, portfolio reflections, and student publications/ presentations) as much as possible, data collection never became onerous for students, faculty members, or administrators. The wide variety of tools used to assess the program included qualitative and quantitative measures, and they were collected from students and faculty members, were collected anonymously and in person, and asked both open-ended and Likerttype questions. The goal of this multifaceted assessment was to triangulate the most comprehensive picture possible of this academic program in the areas of program rigor, student learning (actual and perceived), student satisfaction, and faculty experience and perceptions. 


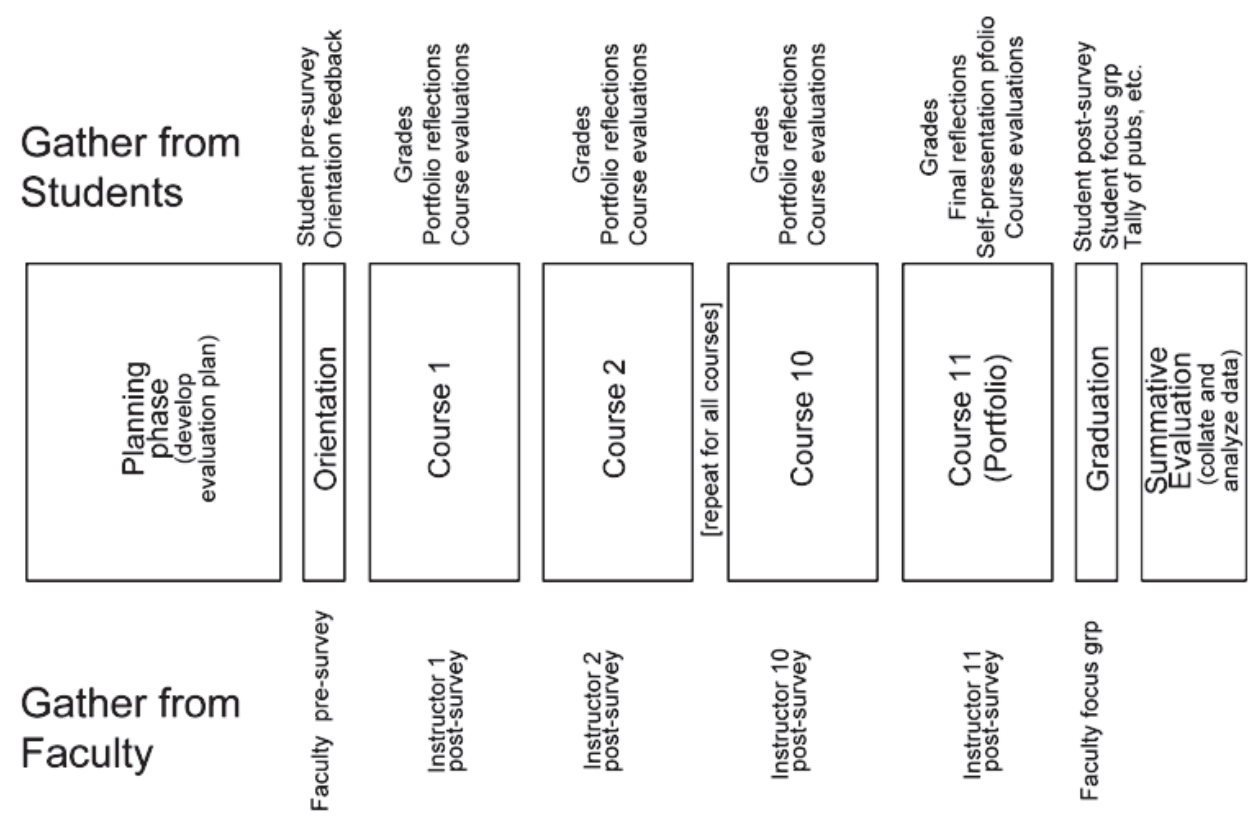

Figure 1. Timeline of assessment activities in study

\section{Results}

\section{Academic Rigor and Workload}

Overall, the data supported the developers' aspiration that the program would be academically rigorous and promote student accomplishment of program goals and competencies and that both students and faculty would value the program as an exceptional learning experience. Online degreegranting courses vary widely in academic quality and are often assumed to have inferior learning outcomes compared to face-to-face courses. ${ }^{5}$ Therefore, it is important that new online programs establish credibility as being academically rigorous. In this case, rigor was determined by analyzing data from a number of quantitative and qualitative sources: curriculum content, student time spent on coursework, program effectiveness in teaching competencies, and student and faculty perceptions of program rigor.

The curriculum was reviewed by seven dental hygiene educators in the program and an instructional technology designer. ${ }^{4}$ The reviewers deemed it not only academically sound, but innovative in the variety and depth of its active learning components, which included community project planning and implementation, a teaching practicum, a capstone project, and both reflective and self-presentation portfolio elements.

Students were asked via course evaluations at the end of each course "How many hours per week would you estimate you spent working on this course?" Cohort One students reported spending a little over twenty hours per week; Cohort Two students reported a little over nineteen hours per week, thus averaging 136.5 hours of student work per three-credit course. Students usually spend one hour in the classroom and two hours of independent work weekly per credit hour in a semester-long course or 135 hours in a fifteen-week semester, three-credit course. ${ }^{11}$ Students in the program thus spent roughly the same amount of time on each course as in traditionally structured face-to-face courses.

Student reflections were analyzed to determine whether the curriculum adequately addressed each program competency. At the end of each course, students were asked to reflect on four competencies of their choice. Their choices give some indication of how well each course addressed the various competencies. For example, administrators would expect students to reflect frequently about items in the leadership competency domain during their 
leadership course and to reflect most frequently on the community competency domain during their two community courses. A notable lack of reflections on a particular competency would suggest that the program did not adequately address that competency in the curriculum. In general, students' choice of competencies matched administrators' expectations. The cohorts reflected on each competency between eight and forty-three times. Twenty-five percent of students in Cohort One and Cohort Two reflected on all twenty-three competencies at least once, and 75 percent reflected on at least twenty of the twentythree at least once. Students reflected on the leadership domain (comprising seven competencies) most frequently during their leadership course; however, the dental hygiene education course and the teaching practicum also showed extensive student reflection on leadership.

Course evaluations and comments from the student focus groups indicated that students found the courses to be rigorous. On a scale of 1 (heavy) to 5 (light), students' rankings of the workload averaged 1.8 for Cohort One and 2.2 for Cohort Two. Sample comments from student focus groups are listed in Table 3. Faculty perceptions of student work also indicated a rigorous program. When surveyed after teaching their first course, 100 percent of faculty members said they believed students learned more course content and participated in more active learning than in face-to-face courses. All faculty members also strongly agreed or agreed that "web-based courses prepare students for real-life experiences." One commented in a focus group that the students "are blown away by what we teach them."

\section{Faculty Experience}

Details on faculty members' experience with, and perceptions of, the program were gathered through both the anonymous surveys and focus groups. Four of the faculty members said teaching online took more time than teaching face-to-face; the other three said it took the same amount of time. The most time-consuming elements were reading group discussion messages and giving detailed feedback to students on discussions and papers. The role of the instructor was perceived by them to have moved from "content expert" to "facilitator." One instructor noted that "Faculty expertise is required in the course development. Once the course is going, the faculty serve more as facilitator." Another mentioned that she was freed from writing new test questions each semester, which was not only a huge time savings, but it let her focus on interacting with students, which she found much more fulfilling than writing multiple-choice questions.

Faculty members did comment that they thought this particular curricular model would not scale well to larger class sizes. "I love teaching online," said one, "but I can't imagine teaching more students with the quick turnaround time for assignments, the amount of time it takes to grade assignments, the number of assignments to grade, and still remain true to other face-to-face course commitments and responsibilities." Another commented: "Apparently next cohort will be double the size and how do we do that? There's no way that you will be able to provide the quality feedback with that large amount of students."

Several commented that it was harder to connect to students online than face-to-face, which in turn made it more difficult to respond to students' needs. "In the classroom, you can get a feel for the personality," one noted. "Online, I don't get the sense as early. By the time I get it, it's usually at the end when I realize what the class is like." Said another: "I was surprised that I got to know many of the students as well as I did. . . . I did feel, however, that if a student was struggling or if I wasn't sure how well a student was really 'getting it,' it was not as easy for me to figure out exactly how to make contact with that individual as it might have been if I was regularly seeing that student face to face in a classroom situation." Finally, several commented on feeling overwhelmed by the workload, for example: "We have a great model here, even though we are

Table 3. Examples of student comments about rigor of the program

Cohort

Cohort Two

Cohort One

Cohort Two

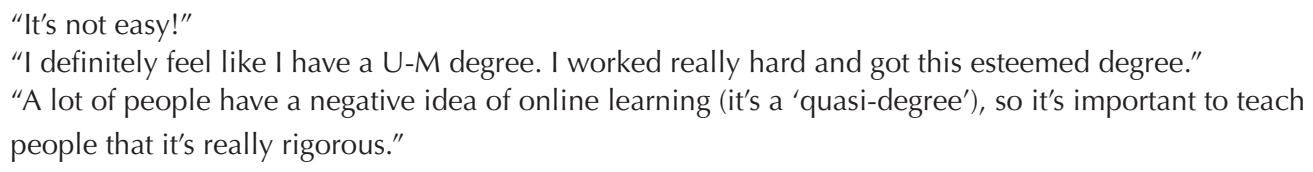


exhausted" and "I agree that the time commitment is overwhelming."

Beginning with Cohort 3, steps will be taken to address faculty workload issues, including the use of teaching assistants and restructuring some assignments. The order of two courses was also reversed, which removed a conflict in which one instructor was teaching online and face-to-face at the same time.

Despite the workload issues, faculty members expressed satisfaction with student learning in the program. In discussing their personal perceptions, they commented on the following items as being positive aspects of the program. Six of the seven faculty members found teaching online to be enjoyable; one was neutral. The faculty members unanimously perceived students learned more course content vs. face-to-face courses. Several preferred the facilitator role required by the program to the lecturer role more common in face-to-face courses. Faculty members perceived that online discussions had weightier content and better participation than live classroom discussions and that students read the course materials more thoroughly and prepared more for discussion sessions. The instructors also saw dramatic improvement in students' writing skills and perceived students as being prepared for real-life experiences upon completion of the program.

Four instructors mentioned that teaching in this program had encouraged them to change how they teach in the classroom. The most common changes were asking more application-based questions on tests, doing more projects, doing less lecturing and more facilitation of student-centered learning, asking more questions, and requiring students to participate more actively in the class session. One instructor went so far as to say, "This is how I always thought I should be teaching and never really had the opportunity to do before."

\section{Student Learning and Professional Growth}

In addition to assessments of the students' learning of course material, this study assessed their professional growth and development and their perception of their own growth. Three measures of student learning were assessed: grades, pass/ fail rates, and student publications and professional presentations. Students must pass all courses with a grade of C- (76 percent) or better. The average of all course grades for Cohort One graduates was $\mathrm{B}+(92$ percent); Cohort Two graduates averaged a B (88.6 percent). The grading scale (Table 4) is demanding: a score of 93 percent must be achieved to earn an A-. Each course in this program was expected to address a certain subset of the program competencies. Each competency was explicitly addressed in at least one course, and assignments were designed to measure student achievement in alignment with the competencies. Every student in these first two cohorts achieved passing grades in every course in the program, indicating achievement in at least a basic level of ability in each competency. Students had several opportunities to share their work with reviewers outside the program, in the form of manuscript submissions and poster presentations. There were a total of six publications and presentations from students in Cohorts One and Two, and one publication and two presentations won awards (Table 5). This recognition suggests that outside reviewers also found the student work to be of high quality.

Students' professional growth and development. The students repeatedly indicated, in course evaluations, surveys, and focus groups, that participating in the program prepared them well for various areas of practice outside the classroom. They clearly valued this opportunity; one student noted in a focus group that she had quit another online program, abandoning a number of credits that would not transfer, to enroll in this program because of the opportunities for student engagement in project-based work in the field (Table 6).

The American Dental Hygienists' Association (ADHA) Professional Roles of the Dental Hygienist (clinician, educator, researcher, administrator/manager, and advocate) are referenced at several points during the program. ${ }^{12}$ Students are made explicitly aware of these roles and are given the opportunity to explore and practice them. The students clearly adopted this broad scope as part of their professional identity. When asked, "How has your understanding of either your own career opportunities or careers for hygienists in general changed?," focus group respondents talked about research, teaching, patient/ community advocacy, public health, library science, increased roles in practice (e.g., developing a recall management system for the office), and graduate study. The students took these expanded roles seriously and talked about them in connection with their own professional goals (Table 6). The students repeatedly mentioned in focus groups that this program helped them become much more confident and cited this increased confidence as one of the key benefits of the program. 
Table 4. Grading scale and final grades for students in Cohorts One and Two

\begin{tabular}{|c|c|c|c|c|}
\hline Grading Scale & Min & Max & Frequency Cohort One & Frequency Cohort Two \\
\hline $\mathrm{A}+$ & 100 & 100 & 0 & 0 \\
\hline A & 95.0 & 99.9 & 4 & 0 \\
\hline A- & 93.0 & 94.9 & 0 & 1 \\
\hline $\mathrm{B}+$ & 90.0 & 92.9 & 1 & 3 \\
\hline B & 87.0 & 89.9 & 1 & 2 \\
\hline B- & 85.0 & 86.9 & 0 & 0 \\
\hline $\mathrm{C}+$ & 82.0 & 84.9 & 0 & 3 \\
\hline $\mathrm{C}$ & 79.0 & 81.9 & 1 & 0 \\
\hline C- & 76.0 & 78.9 & 0 & 0 \\
\hline
\end{tabular}

Table 5. Publications and presentations of students in Cohorts One and Two

\begin{tabular}{|c|c|c|c|}
\hline Cohort & Type & Venue and Date & Award \\
\hline Cohort One & Manuscript & Journal of Dental Hygiene (2010) & $\begin{array}{l}\text { Won the American Dental Hygienists' } \\
\text { Association Sigma Phi Alpha Journalism } \\
\text { Award }\end{array}$ \\
\hline Cohort Two & Article & $\begin{array}{l}\text { Access (publication of the American } \\
\text { Dental Hygienists' Association; 2010) }\end{array}$ & \\
\hline Cohort Two & Article & $\begin{array}{l}\text { Access (publication of the American } \\
\text { Dental Hygienists' Association; 2011) }\end{array}$ & \\
\hline Cohort One & $\begin{array}{l}\text { Poster } \\
\text { presentation }\end{array}$ & $\begin{array}{l}\text { National Oral Health Conference } \\
(2010)\end{array}$ & $\begin{array}{l}\text { Won the American Association of Public } \\
\text { Health Dentistry Dental Hygiene Student } \\
\text { Merit Award for Outstanding Achieve- } \\
\text { ment in Community Dentistry, 2nd place }\end{array}$ \\
\hline Cohort One & $\begin{array}{l}\text { Poster } \\
\text { presentation }\end{array}$ & $\begin{array}{l}\text { American Dental Hygienists' } \\
\text { Association Annual Session (2010) }\end{array}$ & \\
\hline
\end{tabular}

Students' perceptions of their accomplishments. All competency-based programs require proof of outcomes achievement. This program enhances the concept of competency-based education as it also assessed how students perceive their own progress toward competence. Faculty members were generally able to see student growth and accomplishment of program competencies much more easily than students were, presumably due to their outside view of students' learning and their insights into how other students were progressing. This trend was most commonly noticed by faculty members when reading reflective assignments in which students were asked to articulate their experience or abilities. On a number of assignments, faculty members noticed that the students first needed to be reminded of their recent learning and growth before they could adequately complete an assignment. For example, students must complete a résumé during course 1 and then revise that résumé during the first half of the final course. Despite having successfully completed ten courses and numerous "real-life" projects, many students' updated résumés did not look substantially different from their résumés completed during the first course. Significant feedback was required to stimulate students to construct résumés that truly reflected their increased experience.

Comments from students during the focus group indicated they often did not realize the extent of their professional growth until they went back and consciously reassessed their abilities. For example, one Cohort One student commented, "In the oral diseases class, we did a lot of writing which set the stage for the rest of the program. I didn't realize how much my writing was improving in that class, but in Community and Capstone, you really do realize that your 
Table 6. Comments from students in Cohorts One and Two about their professional growth and development

Theme

Comment

Change in understanding of the field and my role in the field

Preparation for real life

Increased confidence
- "Two years ago, I thought I was going to eventually go to dental school. I very quickly realized that what I really wanted to do was to become a DH educator, not a dentist. My teaching practicum really cemented this." (Cohort One student)

- "I've realized how broad a scope they [dental hygienists] have. We don't just have to clean teeth. We can research, teach, advocate. ... there are so many places we can go." (Cohort Two student)

- "I've been a clinical instructor for 6 years and I've seen myself grow and change. . . I'm a lot more confident and a stronger educator than I was 2 years ago. I ask more questions of students, I do a lot more preparation, I use my critical thinking skills and ask my students to do so, and I actually like to read textbooks to stay on the top of my game. I really notice the change." (Cohort One student)

- "For me, the biggest thing that I'm coming out of the program with is that I can walk into a place and create a program. I'm not nervous about 'where do I start?' I now know how to do a program." (Cohort Two student)

- "Before the program, volunteering was simple and straightforward, but after my community project, I understand it's a maze of issues, problems, and red tape." (Cohort Two student)

- "The most important thing [about the ePortfolio] was seeing all our growth—maybe not directly getting a job." (Cohort One student)

- "My [teaching] practicum was one of my most enjoyable experiences because people were looking up to me. I felt confident and capable in a way I never had before." (Cohort Two student)

- "My capstone project was an 'aha moment.' I was able to take everything we'd learned from earlier courses, and it all came together and I knew how to do it all without having to ask because we'd learned it all." (Cohort Two student) writing has come a long way.” These results suggest that if students do not consciously perceive that their competence has increased, they may not perform as competent practitioners. This tendency appeared to be most common among middle-performing students.

The main tool for increasing students' perceptions of their own competence is the portfolio. Students reflect on their accomplishment of program competencies at the end of each course and discuss those reflections with their peers at the beginning of the next course. At the end of the program, students review all their written reflections and develop a Professional Self-Presentation Portfolio to showcase their best work. This repeated reassessment of previous reflections (meta-reflection) gives students the opportunity to judge the accuracy of their selfassessments.

While students generally did not enjoy doing the end-of-course reflections, many expressed appreciation of the final meta-reflection because it helped them comprehend their progress. A student in Cohort One garnered agreement from others when she said in the focus group that she did not like doing the reflections but had an "aha moment" that she could not have completed her portfolio if she had not done reflections all the way along. A Cohort Two student said in a focus group: "I hated doing the reflections at the end of each class; thought it was kind of useless. At the end I reread all my reflections and it all came together for me. I realized it wasn't a waste of time, and I could see my progress." This related directly to student confidence. Students - especially in the more mainstream Cohort Two-commented repeatedly that they "didn't realize how far they'd come" until they completed their final reflections and their portfolios.

\section{Discussion}

\section{Benefits of Triangulation in Program Evaluation}

Triangulation produces a more complete, nuanced assessment than relying on single measures of program success. Quantitative data such as course grades are, of course, mandatory for understanding whether students achieved course learning goals, and 
these data were included in our program evaluation. However, quantitative data only illuminated the most rudimentary facts about student learning. Some of the most significant findings of this program evaluation were discovered through qualitative methods. For example, no quantitative measure was able to show that the most significant student learning related to competencies and reflections happened during the last course, when students reread all their previous reflections and wrote meta-reflections on the competency domains. This information came from content analysis of the meta-reflections and the student focus groups conducted after graduation. If the program evaluation had relied solely on counts of reflections and reflection grades, it would have failed to capture the very significant impact the final reflections had on student learning - namely, that while students demonstrated growth through their reflections, they themselves did not realize how much they had grown over time until they reread their reflections and wrote about their growth over the course of the entire program.

Another qualitative measure, student focus groups, illustrated an additional key benefit the students took away from this program: the monumental changes in their perception of their role within the profession. The graduates expressed interest in pursuing research, community service, and teaching opportunities and felt they had the skills and confidence to do so. These graduates saw themselves as leaders in their profession and had clear ideas of how to set goals and implement advances in oral health care. Not even the numerous ePortfolio reflections communicated to program administration the degree to which students cease to think of themselves as "tooth cleaners" (in the words of more than one student) and begin to think of themselves as population health care advocates, researchers, and effective members of a patient's health care team.

\section{Online Delivery and Good Program Design}

This program, delivered online, was shown to be academically rigorous and was perceived by students and faculty as being a valuable experienceperhaps even more so than typical face-to-face programs. This is consistent with the findings of a 2010 meta-analysis of ninety-nine online learning studies published by the U.S. Department of Education. ${ }^{13}$ However, this does not mean that the online nature of the program caused the high degree of rigor and satisfaction. Rather, it supports numerous statements in the literature that the quality of any program is determined primarily by adherence to proven best instructional practices. ${ }^{13-15}$ Using such well-documented techniques as extensive faculty feedback, active learning situated in contexts relevant to each learner, and clearly defined expectations for learner performance make for a highly motivating, satisfying, and transferrable educational experience., ${ }^{4,16-19}$

However, the online nature of the program did have two distinct advantages. First, it allowed students from a wider range of geography and circumstance (e.g., people working full time, people with inflexible schedules) to matriculate. Second, creating an online program offered the opportunity to design a new program unhindered by legacy habits and teaching practices. Instead of modifying an existing program to be delivered online, the decision was made to "start from scratch" and base the new curriculum entirely on the needs of the field and educational best practices. The program designers felt this decision was pivotal and strongly recommend this approach to others contemplating program development.

\section{Reflection, Meta-Reflection, Confidence, and Competence}

The students participated in repeated reflection and, uniquely, meta-reflection throughout the program. The students also seemed to grasp the full extent of their own increases in competence and highlighted increased confidence as a major feature of the program. This finding raises one new and unexpected question: What are the connections among reflection, meta-reflection, confidence, and competence? Many programs use student reflections (often in portfolio format) to document achievement of program competencies and some have examined the connections between confidence and professional competence, but few have examined the role of meta-reflection on confidence.

The confidence-building effect of meta-reflection seemed most pronounced in this program among middle-performing students. Two of the six Cohort One students and four of the six Cohort Two students remarked on their increased confidence during their focus group. These students represented the middle of the grading curve; none of the two highest-scoring students in either cohort mentioned confidence during the focus groups, and three of the four lowest-scoring students did not participate in the focus groups. These data suggest that middle-performing students made 
greater increases in confidence than either low- or high-performing students.

Combined with the observation that students often do not seem to understand - or at least are not able to articulate - their strengths and accomplishments until the meta-reflection stage, further examination of the role of meta-reflection in student confidence seems warranted. Additional studies by other institutions, resulting in a much larger total number of subjects, would clearly be needed to examine this effect in detail.

\section{Implications for Other Institutions}

Assess all program innovations using a variety of quantitative and qualitative measures. Dentistry and dental hygiene are strongly evidencebased fields, so rigorous program evaluation is required if dental education is to be evidence-based as well. Many schools perceive a need for curriculum innovation due to declining faculty numbers, increased competition for the best students, new teaching technologies, and a desire to graduate toptier practitioners. It is vital that institutions assess existing and future programs to be sure curricular changes do, in fact, have a positive effect. Schools might wish to study effects in a number of different areas, such as student learning, faculty FTE requirements, program costs, or student enrollment - but, in any case, specific, measurable goals must be set and analyzed to provide evidence of effectiveness. The process of using a variety of qualitative and quantitative measures to triangulate program effectiveness can be easily adapted to assess a variety of programs within the health sciences.

Have a fully-fledged program evaluation plan in place before the first courses are taught. Planning all assessment activities ahead of time also makes it easier to gather information as the program progresses. For example, in our program, existing student evaluations were used to feed the program evaluation. Most, such as end-of-course grades, only needed to be tabulated. However, some student evaluation tools needed small changes to ensure they would gather all necessary information. For example, instead of developing additional surveys to ask students about their level of satisfaction with the program, suggestions for orientation, and so on, program-level questions were added to each existing course evaluation. Simple integrations like this saved a significant amount of administrator and student time.
Consider adapting this course design for similar programs. For a more limited group of educators, our specific program plan may prove useful when they are redesigning academic programs. Most likely candidates would include other dental hygiene degree completion programs, nursing degree completion programs, and professional school graduate programs with a smaller cohort size.

\section{Implications for Further Research}

Evaluation research on this program should continue longitudinally to systematically and consistently capture outcomes from a greater number of students and faculty members. It would be particularly useful to determine if the results from the first two cohorts are representative of the experience of the population of dental hygiene degree completion students in general; if faculty perceptions of faculty workload change over time; what subsequent longterm career paths are followed by graduates of the program; and how this program compares to other online degree completion programs in dental hygiene or other health sciences. It could also be useful to engage employers about the graduates of this program to learn more about their perceptions of graduates' employability and the utility of the self-presentation portfolio during the hiring process.

Additional research is also needed on the question of the value of meta-reflection, especially as it relates to the confidence and performance of middleachieving students. It may be argued that measures to improve the performance of middle-achieving students can help the profession by developing additional excellent leaders, teachers, and clinicianswhereas high-performing students are already at the "excellent" level and low-performing students are unlikely to improve from "marginal" to "excellent" performance. Specific research questions include the following: 1) How does student confidence correlate to performance in clinical, educational, advocacy, policymaking, and administrative activities? 2) Does meta-reflection provide significant gains in confidence/competence beyond simple reflection, and is there a difference in the gains made by low-, middle-, and high-performing students? and 3) In what cases is the time involved in guiding students through reflection and meta-reflection most warranted?

\section{Limitations of This Study}

The number of students in the two cohorts studied were quite small $(\mathrm{N}=7, \mathrm{~N}=9)$, so some of 
the specific curricular innovations and assessment measures used in this program may not be applicable to programs with larger student bodies. For example, reflective portfolios may not be feasible with a cohort of 125 students. However, it may be possible for faculty members to require one reflective question on each final exam. Likewise, an exit interview with every student may not be possible, but a post-graduation focus group of eight students representing a range of grade point averages might be feasible. Whatever specific assessment measures are used, however, the program evaluation method described (planning a triangulated summative evaluation before the details of individual courses are developed) should be widely applicable to academic programs in a number of fields.

\section{Conclusions}

This study arrives at three main conclusions about summative program evaluation, the high quality of this program, and the relationship between student meta-reflection and professional behavior. First, using a wide array of quantitative and qualitative measures provides a comprehensive and nuanced picture of program results. Quantitative measures, such as grades, publication/presentation counts, and survey results, should be combined with qualitative measures, such as focus groups and student reflections, to triangulate a more complete picture of program evaluation. Important details of a program's strengths and weaknesses may be lost if only quantitative measures are analyzed. For best results, summative evaluation plans should be in place before the program begins, and student assessment tools should be repurposed for program evaluation.

Second, applying this method of program evaluation, it was determined that the University of Michigan Dental Hygiene Degree Completion E-Learning Program is an academically rigorous program. It requires significant active learning and application of classroom concepts to actual real-life situations. It effectively teaches program competencies, and students can articulate how they have achieved the program's competencies. Both students and faculty members expressed high levels of satisfaction with the program.

Third, further study is needed to confirm that student meta-reflection and confidence are closely connected to each other and to student performance. Results from this program suggest that while student reflection on achievement of program competencies is helpful, students often only experience a dramatic increase in understanding of their own abilities when they reread those reflections and write meta-reflective summaries. This process seems to increase their confidence in their own abilities, which could in turn increase their willingness to move into leadership roles in their current jobs or in professional roles in education or at the community or state level. Further inquiry is warranted to study these implied connections in more detail.

\section{REFERENCES}

1. Haden NK, Andrieu SC, Chadwick DG, Chmar JE, Cole JR, George MC, et al. The dental education environment. J Dent Educ 2006;70(12):1265-70.

2. Luke R, Solomon P, Baptiste S, Hall P, Orchard C, Ruckholm E, et al. Online interprofessional health sciences education: from theory to practice. J Contin Educ Health Prof 2009;29(3):161-7.

3. Wiggins G, McTighe J. Understanding by design. $2^{\text {nd }}$ ed. Alexandria, VA: Association for Supervision and Curriculum Development, 2005.

4. Gwozdek AE, Springfield ES, Peet MR, Kerschbaum WE. Using online program development to foster curricular change and innovation. J Dent Educ 2011;75(3):339-50.

5. Seaman J. Online learning as a strategic asset - the paradox of faculty voices: views and experiences with online learning. Babson Park, MA: Babson College, 2009.

6 . Thurmond VA. The point of triangulation. J Nurs Scholarsh 2001;33(3):253-8

7. Mitchell TV, Gadbury-Amyot CC, Bray KK, SimmerBeck M. Advanced degree-seeking students' satisfaction with online courses at UMKC: an early investigation. J Dent Hyg 2007;81(3):e1-e8.

8. Wills CE, Stommel M. Graduate nursing students' precourse and postcourse perceptions and preferences concerning completely web-based courses. J Nurs Educ 2002;41(5):193-201.

9. Lincoln Y, Guba E. Handbook of qualitative research. Thousand Oaks, CA: Sage Publications, 1994.

10. Glaser BG, Strauss AL. The discovery of grounded theory: strategies for qualitative research. Chicago: Aldine Publishing Co., 1967.

11. Wolanin TR. The student credit hour: an international exploration. New Dir High Educ 2003;122:99-117.

12. American Dental Hygienists' Association. Standards of clinical dental hygiene practice. Chicago: American Dental Hygienists' Association, 2008.

13. Means B, Toyama Y, Murphy R, Bakia M, Jones K. Evaluation of evidence-based practices in online learning: a meta-analysis and review of online learning studies. Washington, DC: U.S. Department of Education, Office of Planning, Evaluation, and Policy and Program Studies Service, 2010.

14. Kelting-Gibson LM. Comparison of curriculum development practices. Educ Res Q 2005;29(1):26-36. 
15. Robinson MR. A case study examining the relationship between online course design quality and course effectiveness at a community college. Ph.D. dissertation, Capella University, 2009.

16. Gustafson KL, Branch RM. Survey of instructional development models. $4^{\text {th }}$ ed. No. ED477517. Syracuse, NY: ERIC Clearinghouse on Information and Technology, 2002.
17. Bristol TJ. Evidence-based learning for nurse educators. Des Moines: Center for Health Workforce Planning Bureau of Health Care Access, Iowa Department of Public Health, 2006.

18. Fin LD. The power of course design to increase student engagement and learning. Peer Rev 2007;9(1):13-7.

19. Driscoll M. Psychology of learning for instruction. $2^{\text {nd }} e d$. Needham Heights, MA: Allyn and Bacon, 2000. 